\title{
Seven Steps to Successfully Implementation of Green Supply Chain in Iran
}

\author{
${ }^{1}$ Hamidreza Soheili \\ 2Abdolreza Mohhammadi \\ ${ }^{3}$ Vahid Naderi Dareshori \\ ${ }^{4}$ Omid Veisy

\begin{abstract}
${ }^{1}$ Faculty member at the officer University of Imam ${ }^{2} \mathrm{MS}$ in Information Technology Management, Young Researchers and Elites Club North Tehran Branch, Islamic Azad University, Tehran, Iran ${ }^{3}$ Faculty member at the officer University of Imam ${ }^{4}$ Faculty member at the officer University of Imam
\end{abstract}

\section{Doi:10.5901/mjss.2016.v7n5s1p149}

\section{Abstract}

\begin{abstract}
A new approach that has been dominant in recent years on management of operations is supply chain management (SCM) approach. Supply chain is network of facilities and distribution centers performing the tasks of procurement of raw materials, turning it into final and intermediate products and distribution of these products for customer. On the other hand, world is faced with issues such as global warming, pollution, increasing the quantity of greenhouse gases and that these issues could potentially lead to the extinction of the human race. Therefore, preserving the environment and strategies related to it was included in priority of programs, as an important organizational innovation. Organizations needed to focus on profitability and competitive advantage on one hand, and eliminating or minimizing the wastes (energy, emissions, chemical / hazardous solid waste) on the other hand. It was here that the idea of green supply chain was proposed and soon it attracted the attention of everyone. The present research is applied in terms of the objective, and it is analytical and descriptive is terms of methodology. Population of study included customers of various organizations and companies, which their number is 320 people, and 175 of them were selected as sample of study using Cochran table. Results of this study suggest that 10 main steps of study have been organized in 7 steps and 5 dimensions, and out of 10 steps proposed, three steps were eliminated and 7 steps were obtained. Using ANP method, they were ranked that the most important of them was using the modern technology.
\end{abstract}

Keywords: identification- step - implementation- green supply chain - Iran ANP

\section{Introduction}

In recent centuries, industrial development has been replaced by sustainable development and the environmental consequences and unresponsiveness of earth resources have become a major concern. Industry managers, especially in developed countries, are looking for ways to protect the environment and to increase the performance of their organizations. Green supply chain is a type of supply chain in which environmental requirements are observed and products return to supply chain after spending their useful life. Its main goal is reducing the environmental pollutions from upstream to downstream of supply chain (Chen et al 2010). In this regard, paying attention to green supply chain, and identifying the steps involved in implementing the supply chain are very effective and helpful. It is the main goal of the current study.

\section{Overview of Research}

\subsection{Problem statement}

Today, environmental pollution is the main problem that people are face with it every day and release of toxic gases mainly from industrial production is the major concern in this regard. To overcome this problem of environmental pollution, the manufacturing industries should apply green concepts in their supply chain. Meanwhile, environmental concerns have become a very important factor in manufacturing industries. In today's competitive world, relationship with 
suppliers and customers plays an important role in the growth of a company. In general, companies are looking for higher profit both themselves and their customers. These advantages can be achieved by a formal process known as supply chain (Chen et al., 2010). Currently, industries in the global and competitive market are under pressure for environmental management that in fact these pressures are created by domestic and external resources (Sarkis et al 2008). Several studies have shown that adopting green supply chain management by organizations can lead to improved environmental performance (Zhu et al., 2004). Greening the supply chain is an opportunity for those who are concerned about sustainable consumption and environmental business performances. From a macro perspective, it is very important to pay attention to green issues as a mechanism to increase the ability to design green products and as a means to create markets for green products compatible with the environment. The Green supply chain requires new inputs causing opportunity for companies to invest on designing and manufacturing greener products and to solve the sustainability requirements. This includes not only consumer goods, but also includes inputs from suppliers (Shio et al., 2004). Based on what was said, the most important concern of the researcher to do the current study was lack of knowledge on the way to implement green supply chain in Iran. By introducing and prioritizing the key steps of successful implementation of green supply chain, it will be extremely helpful in this regard.

\subsection{Importance of study}

Greening the supply chain both at the individual level and at the national level have advantage for the company. At the individual level, green supply chain programs lead to certain competitive advantages, such as lower costs, greener products and better integration with suppliers. At the national level, green supply chain can create markets for green products, and it can adapt suppliers with the environment issues. Greening the supply chain can improve competitive position of companies by reducing costs (Trowbridge, 2003).

\subsection{Objective of study}

- Identifying key steps for successfully implementing of green supply chain in Iran.

- Prioritizing the key steps for successfully implementing of green supply chain in Iran.

\subsection{Research question}

- What are the key steps for successfully implementing of green supply chain in Iran

- What is the priority for key steps of successfully implementing of green supply chain in Iran

\section{Review of Literature}

Association of Industrial Research in Michigan State University introduced Green Supply Chain Management in 1996 that it is in fact a modern management model to protect environment. In terms of life cycle, Green supply chain management includes all stages including raw materials, product designing and manufacturing, product sales and transportation, product using and recycling of them. Using supply chain management and green technology, companies can reduce negative environmental impacts and achieve optimal use of resources and energy (Eksionghi and Wei, 2007). Greening the supply chain is the process of taking into account the standards or environmental considerations throughout the supply chain. Green supply chain management integrate supply chain management with environmental requirements at all stages of product design, selection, and providing green supply chain is the process of taking into account the standards or environmental considerations throughout the supply chain. Green supply chain management integrates supply chain management with environmental requirements at all stages of product design and selection, raw material supply, manufacturing, distribution and transmission processes, delivery to the customer. Finally, after the consumption, it includes waste management and reuse in order to maximize the amount of energy and resource efficiency to improve performance (Sarkis, 2006). In examining the environmental impact of supply chain activities, the products impacts on environment are analyzed using holistic approach (including analysis of product life cycle from the beginning to the end of its life). In this approach, all the ecological effects (the habits and lifestyle of organisms and their interaction with the environment) of any activity at different stages of the product life cycle, including product concept, design, procurement of raw materials, manufacturing, assembly, maintenance, packaging, transportation, and re-use of product are measured and they are considered in product design (Farahani et al., 2009). In 1990s in line with improvement in manufacturing 
capacities, managers of industries realized that materials and services received from various suppliers have great impact on increasing the organization capacities to deal with customers' demands that this had great impact on concentration of organization and supply bases. Managers also found that only producing a high-quality product is not sufficient, in fact, supplying products with criteria of the customer (when, where, how) and high quality products based on their wanted cost create new challenges. As a result, they realized that these changes are not sufficient in the long-term for their organization management. They were involved in in network management of all companies and firms organization inputs supplied them directly and indirectly as well as network of companies related to delivery and after sale service for customer. Accordingly, the approaches of "supply chain" and "supply chain management" emerged.

\subsection{Definition of green supply chain}

Srivastava (2007) defined green supply chain as follows: "considering the environmental issues in supply chain management, including product design, selection and sourcing of materials, manufacturing process, the final product delivery to the customer and product management after consumption and spending its useful life".

Although concepts of sustainable supply chain management and green supply chain management are used instead of each other in literature, these two concepts differ little from one another. Sustainable supply chain management includes economic dimensions and environmental and social sustainability. Thus, the concept of sustainable supply chain management is broader than green supply chain management and green supply chain management is part of a sustainable supply chain management (Farahani et al., 2009). In the past, the product life cycle includes the processes from designing to consumption. However, with environmental management approach, it includes the processes of raw materials procurement processes, designing and manufacturing, using and recycling, reusing, and forming a closed loop of material flow is to reduce resource consumption and reduce destructive environmental impacts.

\subsection{Components of green supply chain}

Green design of company must include complete description of environmental, human health and product safety issues in the process of obtaining raw materials, manufacturing, and distribution, and its main aim is to prevent pollution at the source. Green Design Company must complete description of environmental, human health and product safety in the process of acquisition of raw materials, manufacturing, and distribution to prevent pollution at the source.

Green materials refers to materials that use less energy and resources and creates less noise, non-toxic and does not cause environmental degradation. Green Productivity is much larger than all management efficiency. Green manufacturing is also known as clean manufacturing. In various stages of development or in different countries green manufacturing has different names.

Green marketing: green marketing objective is creating harmony between goals of economic development, environmental and social development, and enhanced perception of the sustainable development.

Green consumption: it means trying to choose environmentally friendly products and services for use and deal with the waste products that may be harmful to the environment.

\subsection{Background of study}

Celeh and Silver proposed the concept of green supply chain for the first time in 1989. In an article, Hua linked two concepts of green supply chain management and green productivity together. He believes that observing environmental considerations and supply chain management provide an opportunity so that supply chain help organizations to enhance their productivity, quality and environmental performance through continuous information flow. Huang (2013) proposed the issue of green purchasing, so that in the manufacturing process and supply of products, large quantities of raw materials, office supplies, etc. are required. In order that companies can produce green products, they should make use of materials and products compatible and consistent environmental standards. Therefore, organizations in dealing with their suppliers (in order to maintain market share or even just to survive) should pay attention to environmental issues. Some of the reasons for that companies show willingness for green purchasing is a response to consumer interest in environmentally friendly products and making distinguish between products of their company with products of competitors and saving in costs. Most companies consider a principal for more compatibility with the environment that some of these principles are providing a list of chemicals that should be applied, providing a list of acceptable products, working closely with suppliers to increase environmental performance and to considering the multiple features of environment when 
making a decision about purchasing.

Rao (2010) believes that companies should form teams to investigate and select suppliers. Such action guarantees the following items:

- Compatibility or adaptability of products or services produced by the company with environment.

- preventing pollution at the source;

- reusing of materials;

- increasing the volume of recycled materials in manufacturing;

- optimizing the processes so that wastes, either harmful or non-harmful, are minimized,

- Re-designing of products in such a way that their environmental adverse effects are minimized.

However, according to Zhou et al (2013) there are obstacles and pressures for selection of suppliers from environmental issues perspective. Some of these pressures include governmental environmental laws and regulations, environmental mission of company purchase, potential liability for disposal of hazardous materials and the cost of disposal of hazardous substances. Kushibu (2008) believes that merely manufacturing and supply of green products to markets are sufficient for manufacturers. They also need consumers who are demanding green products. In other words, green companies need green markets. According to Yu (2006), this knowledge has been created among consumers that their purchase affects the environment and they have been encouraged that pay attention not only to quality of product, but also consider the conditions in which goods are produced. Green consumption began in Europe firstly and peaked in the 1980s and it was more severe in Germany. Consumers have supported those producers who are accountable on environmental issues. As a result, green consumerism has led to the fact that environment recognition to become a competitive advantage for manufacturers. The green consumerism also emphasizes that manufacturers should be compatible with environmental standards to ensure their products. Brad and Raze (2014) believe that organizations should take advantage of their employees by adopting participatory management structures and processes (to use the ideas, innovation and creativity of employees) in order to achieve better environmental results in moving towards a green supply chain management. Many experts recommend using green teams. Stages of applying a green team include environmental review, developing an environmental plan, developing of an environmental unit, creating working groups for environmental activities, determining organization's environmental goals, combining environmental problems with the framework of organization monitoring, and review of environmental plan achievements. Harris and Crane (2006) suggest that moving towards green activities and the implementation of green management mainly depend on cultural green changes. Cultural green changes require mix of environmental responsibility and current culture of organization. This emphasis on cultural green changes is an incentive to attempt in line with conceptualizing green culture values of the organization. Some of these key values are bringing environmental considerations throughout the value chain of the organization, modification of economic objectives, and regarding ethics, spirituality and futurism. Rao (2010) stated that the green industry mainly depends on greening the product, because the pollutants are mainly created during the process of manufacturing of goods and services. The application of green manufacturing of innovative techniques is mainly depend on creativity and innovative techniques. This requires close cooperation with employees and suppliers. There is common framework for the application of green manufacturing including:

Cleaner manufacturing: cleaner manufacturing is continuous application of a preventive environmental strategy applicable to products, processes and services and it considers causes of pollution. The aim of this view is to prevent contamination of the primary sources of manufacturing.

Environmental efficiency: The aim of this view is to maintain and protect resources. This view tends to produce goods and services with optimal use of manufacturing inputs and thereby minimize waste and control the pollution.

Lean manufacturing: similar to previous concept, this view aims to minimize non-value added activities, to reduce the use of resources, and thereby increase the efficiency.

In another study, Zhou et al (2013) investigated the implementation of green supply chain because of increasing pressure on managers to improve both environmental and economic performance of China's automobile industry. Some of the factors imposing pressure organizations to adopt and implement green supply chain management are as follows:

Consumer pressure, shortage of resources, green strategies of competitors, environmental mission of organization, and national and international laws and regulations.

$\mathrm{Su}$ and $\mathrm{Hu}(2013)$ assessed the major approaches in implementing green supply chain management. They have identified 20 approaches and prioritized them through fuzzy hierarchical analysis techniques. The first three priorities obtained in this study include establishing an environmental database for products, senior management support, and environmental assessment of suppliers. Zhou et al (2013) identified 22 components for evaluating green supply chain management in some China industries such as electronics, petrochemicals and automobiles. They classified these 
criteria in five categories, including internal environmental management, green purchasing, and collaboration with customers, recycling, and environmental design. Ninlavan et al (2013) identified criteria for evaluating green supply chain management in Thailand in the electronics industry. They classified these criteria in four categories including green procurement, green manufacturing, green and logistics distribution. By offering a multi-objective model, Wang et al. (2014) optimized green supply chain. Considering factors such as transportation cost, the flow of products through the supply chain and investment to protect the environment, they have developed their research model. Ape et al (2014), provided a comprehensive approach to model and evaluate the performance of supply chain. For this evaluation, they considered six criteria of product reliability, employee satisfaction, customer satisfaction, on-time delivery, growth of profitability and efficiency. Kutzab et al (2014) identified 34 green supply chain indicators in the retail area identification and placed these indicators in eight categories of environmental management systems, energy use, and attention to inputs, products, packaging, transportation, consummation, and wastes. Large and Thomson (2014) have identified green supply chain management indicators and provided them under 5 components of green supply management capabilities, green purchasing, environmental liability, environmental assessment of suppliers and collaboration with suppliers. below.

Based on what was said, the most important factors in successfully implementation of green supply chain are as

1. Criteria necessary for reducing the consumption of raw materials

2. The use of new technologies for the efficient use of energy

3. Training and providing proper consumption models of energy

4. Regulating necessary criteria to reduce energy consumption

5. Observing the standards required in the purchase of machinery, equipment and tools from technical and environmental point of view

6. Continuous analytical examining of the situation of machinery and examining its exhaustion status so that causes no environmental pollution and high-energy consumption

7. Analytic examining of all stages of the manufacturing process from principal point of view of saving in resources

8. Advanced equipment to transport materials, final product and waste to minimize waste

9. Recycling of wastes within the company

10. Contamination of water, soil and air by the final product

11. Contamination of water, soil and air by the waste

12. Contamination of water, soil and air in the process of reprocessing

13. Product recycling at the end of its useful life

14. Training and advising people on environmental issues

15. Providing an environment to study and make recommendations on environmental issues

16. Recycling of wastes outside the company

17. Promoting green culture in the workspace of company

18. Creating controlling and monitoring systems o observe environmental standards

19. Creating informing system to employees

20. Supporting green supply chain by senior and middle managers

21. Environmental TQM (Total Quality Management Environment)

\section{Methodology}

Methodology in behavioral sciences is determined according to following criteria 1) objective of study 2) data collection method 3) implementation of study (Kalantari, 2003).

\subsection{Methodology based on objective}

This study is applied in terms of objective and it is descriptive-correlational study in terms of method of study.

\subsection{Methodology based on data collection method}

The present research is descriptive and non-experimental in terms of data collection and method of data analysis in which researcher to find an answer for the question during the research process. 


\subsection{Research methodology based on implementation of study}

The present study is survey in terms of implementation.

\subsection{To collect data, the following methods were used:}

A. Library studies: to collect on the research theory and literature, library resources, articles, books were used.

B. Field studies: To collect data for analysis for analysis, green supply chain questionnaires was used.

\subsection{The population, sampling method and sample size:}

The sampling method used in this research is stratified sampling. As there are large number of organizations with different characteristics involved in green supply chain, stratified random sampling was used. Organizations have been considered as separate classes that a sample has been selected among them. This sampling causes that sampling is conducted randomly among all people in various organizations leading to higher generalizability of the results to the entire organization. To determine sample size, Morgan table will be used and number of target community was 320 people, 175 of them were selected as sample of study.

\subsection{Data analysis methods and tools}

Firstly, Kolmogorov - Smirnov (K-S) was used to examine normal distribution of data. Then, factorial analysis procedure is performed on main components proposed by the Kaiser based on calculations on correlation matrix of variables. Then, this matrix is converted to factors matrix through calculation. Load factors of each variable should be interpreted on factors to introduce main structure of variables. Due to various reasons, we are usually faced with numerous variables. For a more detailed analysis of the data, and to achieve more scientific and operational results, researchers are looking to reduce the size of the variables and the formation of a new structure for this purpose, and factorial analysis is used for this purpose. Factor analysis tries to identify the underlying variables or factors in order to explain the correlation pattern between the observed variables. Factor analysis has a very important role in identifying the latent variables (Kalantari, 2003). This study also uses factorial analysis method to analyze the factors and uses ANP decision technique to prioritize them.

\section{Analysis of Data}

\subsection{Proposed steps identified}

Based on the studies conducted as well as experts points of view in this area, 10 steps have been provided out of 21 identified steps as Table 1 shows.

Table 1: Proposed steps identified

\begin{tabular}{|c|c|}
\hline & Steps \\
\hline \multirow{10}{*}{ 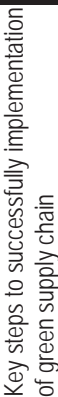 } & The use of new technologies for the efficient use of energy \\
\hline & Training and providing proper energy consumption patterns \\
\hline & Establishing controlling and monitoring systems to observe environmental standards \\
\hline & regulating criteria and standards to reduce energy consumption \\
\hline & Observing standards required in the purchase of machinery and equipment from technical and environmental point of view \\
\hline & Supporting of green supply chain by senior and middle managers \\
\hline & product recycling at the end of its useful life \\
\hline & Analytical investigation of all stages of the manufacturing process from the principal point of view of saving in resources \\
\hline & Promoting green culture in the workspace \\
\hline & Environmental total quality management \\
\hline
\end{tabular}




\subsection{Analysis of the proposed framework}

In this section, we test the proposed framework described above. In order to extract the main steps, the following cases were calculated.

\subsection{Reliability}

Reliability is calculated by Cronbach's alpha. The alpha value greater than 0.7 indicates relatively high reliability.

Table 2: Cronbach's alpha

Reliability Statistics

\begin{tabular}{|c|c|}
\hline Cronbach's Alpha & N of Items \\
\hline 820 & 98 \\
\hline
\end{tabular}

\subsection{Kaiser and Bartlett test}

It is an index of sampling adequacy examining the smallness of correlation among the variables and thereby specifies that if variance of research variables is affected by common variance of some latent and main factors or not. This index is in the range zero to one. If the value of the index is close to one, data for factorial analysis are appropriate (usually less than 0.6), otherwise, the factorial analysis results are not appropriate for considered data. In this research, this claim was proven and considered data are appropriate for factorial analysis. (Mansouri, 2007).

Table 3: Coefficients of KMO and Bartlett's test

\section{KMO and Bartlett's Test}

\begin{tabular}{|ll|r|}
\hline Kaiser-Meyer-Olkin Measure of Sampling Adequacy. & .886 \\
Bartlett's Test of & Approx. Chi-Square & 5.839 \\
Sphericity & df & 6 \\
& Sig. & .031 \\
\hline
\end{tabular}

\subsection{Scree plot graph}

Tis graph is used to extract the main components. Here values for Eigen value were considered greater than 1 in the calculation. If Eigen value of 1, a line is drawn in line with horizontal axis on the vertical axis, the number of points that located above the line indicates number of extracted steps.

\subsection{Rotated component matrix}

In order to investigate that which of the steps has greater absolute load on extracted components, rotated component matrix component is calculated. In order to strengthen of the results, the minimum value was considered 0.6 (Azar, 2006).

\subsection{Analysis of the proposed steps}

For each of the 10 steps proposed, the mentioned analytical stages will be performed.

\subsection{Analysis of 10 steps}

Ten proposed steps have been shown in table below by describing characteristics along with related codes. 
Table 4: Proposed table and 10 steps

\begin{tabular}{|c|c|c|}
\hline & Steps & Index Code \\
\hline \multirow{10}{*}{ 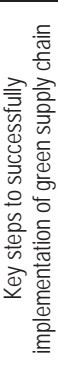 } & The use of new technologies for the efficient use of energy & 1=B1 \\
\hline & Training and providing proper energy consumption patterns & $2=\mathrm{B} 2$ \\
\hline & Establishing controlling and monitoring systems to observe environmental standards & 3=B3 \\
\hline & regulating criteria and standards to reduce energy consumption & 4=B4 \\
\hline & Observing standards required in the purchase of machinery and equipment from technical and environmental point of view & $5=\mathrm{B} 5$ \\
\hline & Supporting of green supply chain by senior and middle managers & $6=\mathrm{B} 6$ \\
\hline & product recycling at the end of its useful life & $7=\mathrm{B} 7$ \\
\hline & Analytical investigation of all stages of the manufacturing process from the principal point of view of saving in resources & $8=\mathrm{B} 8$ \\
\hline & Promoting green culture in the workspace & 9=B9 \\
\hline & Environmental total quality management & $10=\mathrm{B} 10$ \\
\hline
\end{tabular}

Descriptive statistics related to each of 10 steps

Table 5 - Descriptive statistics related to 10 steps
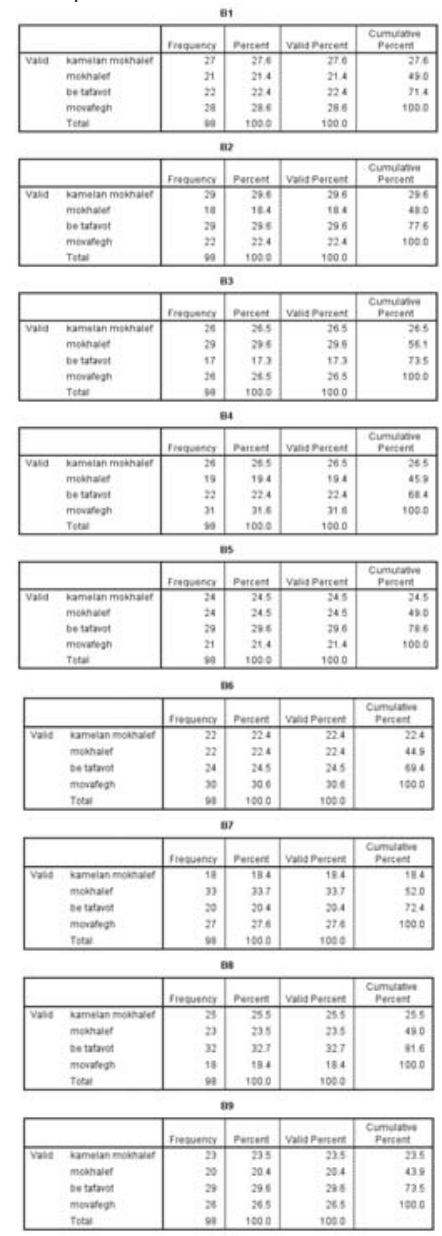

ถ⿻

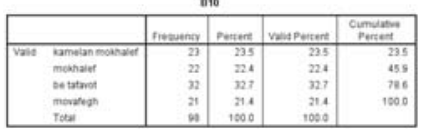




\subsection{Scree plot graph}

In Figure below, Scree Plot of 10 proposed steps to extract key steps has been shown. As this Figure shows, the number of extracted components (greater than value 1 ) is 5 axes.

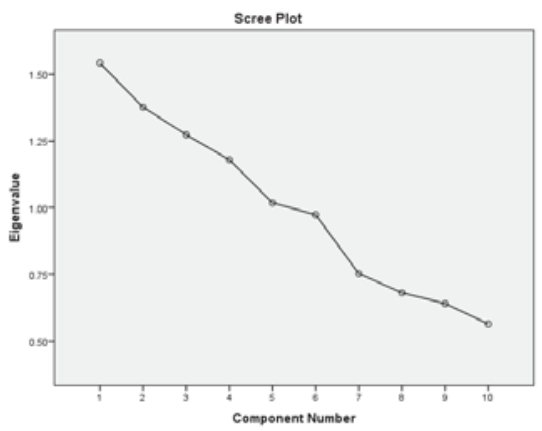

Figure 1: Scree Plot graph for 10 steps

\subsection{Rotated component matrix}

It is observed that each of proposed steps has appropriate absolute load after 5 rotations. Therefore, variables with absolute factorial load value greater than 0.55 in 5 steps are organized according to the figure below (it is evident that steps B3- B4- B8 are eliminated).

Table 6: Rotated component matrix for 10 steps

\begin{tabular}{|c|c|c|c|c|c|}
\hline \multicolumn{6}{|c|}{ Component Matrix ${ }^{a}$} \\
\hline & \multicolumn{5}{|c|}{ Component } \\
\hline & 1 & 2 & 3 & 4 & 5 \\
\hline B1 & .421 & .099 & .073 & .718 & .185 \\
\hline B2 & .347 & -.465 & .250 & .079 & .589 \\
\hline B3 & -.512 & .206 & -.058 & .444 & .062 \\
\hline B4 & -.295 & .400 & .411 & -.135 & -191 \\
\hline B5 & .001 & .505 & .591 & .064 & .232 \\
\hline B6 & .337 & .703 & -.001 & .198 & .148 \\
\hline B7 &. .573 & .028 & -.168 & .202 & .127 \\
\hline B8 & .460 & .248 & -.482 & .069 & -.416 \\
\hline B9 & .252 & .324 & -.317 & -.591 & .370 \\
\hline $\mathrm{B} 10$ & .423 & -.175 & .568 & .056 & -.440 \\
\hline
\end{tabular}

Final table of 10 steps

Based on analysis performed, 7 steps are provided in Tbale 7.

Table 7- Main and final table for 10 steps

\begin{tabular}{|c|c|c|}
\hline & Components & Steps \\
\hline \multirow{7}{*}{ 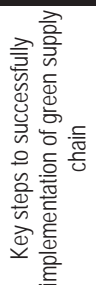 } & Recycling of Products & product recycling at the end of its useful life \\
\hline & Senior management support & Supporting of the green supply chain by senior managers and middle \\
\hline & \multirow[t]{2}{*}{ Total Quality Management } & $\begin{array}{l}\text { Observing the standards required in the purchase of machinery and equipment from technical and } \\
\text { environmental point of view }\end{array}$ \\
\hline & & Environmental total quality management \\
\hline & \multirow{2}{*}{ New Technology } & The use of new technologies for the efficient use of energy \\
\hline & & Promoting green culture in the workspace \\
\hline & Training of employees & Training and providing proper energy consumption patterns \\
\hline
\end{tabular}




\subsection{Analyzing and prioritizing the steps}

ANP is a model for assessing readiness of organization to calculate the weight of the features according to the secondary criteria. This procedure is applied widely because it can be sued in complex and dynamic environments due to the ability in replacing the hierarchy that is one feature AHP method. In addition, by applying changes in the levels of decisionmaking and isolation and giving weight to common features, it is even able to obtain more reliable results compared to very large and complex matrices that include the same features that are in the form a subset of interdependent pairs. In order to prioritize the most important determined steps, the ANP method was used. In this study, instead of using hourly super matrix, the concept of hourly and Takizawa in AHP method was used. Due to the uncertainty of respondents to the questions raised, triangular fuzzy data were used. At this stage, in order to analyze the data, views of geometric mean were used. Then, the obtained composite matrices were used. (Mansouri, 2007)

Table 8: Pairwise comparisons of extracted steps

\begin{tabular}{|c|c|c|c|c|c|c|c|c|c|c|}
\hline Step & 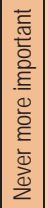 & 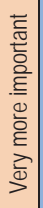 & 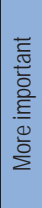 & 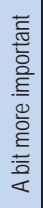 & $\mid \begin{array}{l}\overline{\widetilde{J}} \\
\overline{\mathrm{w}}\end{array}$ & 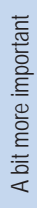 & 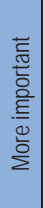 & 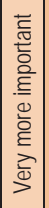 & 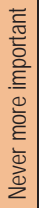 & Step \\
\hline Product recycling & $\square$ & $\square$ & $\square$ & $\square$ & $\square$ & $\square$ & $\square$ & $\square$ & $\square$ & senior management support \\
\hline Product recycling & $\square$ & $\square$ & $\square$ & $\square$ & $\square$ & $\square$ & $\square$ & $\square$ & $\square$ & Observing required standards \\
\hline Product recycling & $\square$ & $\square$ & $\square$ & $\square$ & $\square$ & $\square$ & $\square$ & $\square$ & $\square$ & Environmental total quality management \\
\hline Product recycling & $\square$ & $\square$ & $\square$ & $\square$ & $\square$ & $\square$ & $\square$ & $\square$ & $\square$ & New technologies \\
\hline Product recycling & $\square$ & $\square$ & $\square$ & $\square$ & $\square$ & $\square$ & $\square$ & $\square$ & $\square$ & Promoting green culture \\
\hline Product recycling & $\square$ & $\square$ & $\square$ & $\square$ & $\square$ & $\square$ & $\square$ & $\square$ & $\square$ & Training \\
\hline senior management support & $\square$ & $\square$ & $\square$ & $\square$ & $\square$ & $\square$ & $\square$ & $\square$ & $\square$ & Observing required standards \\
\hline senior management support & $\square$ & $\square$ & $\square$ & $\square$ & $\square$ & $\square$ & $\square$ & $\square$ & $\square$ & Environmental total quality management \\
\hline senior management support & $\square$ & $\square$ & $\square$ & $\square$ & $\square$ & $\square$ & $\square$ & $\square$ & $\square$ & New technologies \\
\hline senior management support & $\square$ & $\square$ & $\square$ & $\square$ & $\square$ & $\square$ & $\square$ & $\square$ & $\square$ & Promoting green culture \\
\hline senior management support & $\square$ & $\square$ & $\square$ & $\square$ & $\square$ & $\square$ & $\square$ & $\square$ & $\square$ & Training \\
\hline Observing required standards & $\square$ & $\square$ & $\square$ & $\square$ & $\square$ & $\square$ & $\square$ & $\square$ & $\square$ & Environmental total quality management \\
\hline Observing required standards & $\square$ & $\square$ & $\square$ & $\square$ & $\square$ & $\square$ & $\square$ & $\square$ & $\mathrm{E}$ & New technologies \\
\hline Observing required standards & $\square$ & $\square$ & $\square$ & $\square$ & $\square$ & $\square$ & $\square$ & $\square$ & $\square$ & Promoting green culture \\
\hline Observing required standards & $\square$ & $\square$ & $\square$ & $\square$ & $\square$ & $\square$ & $\square$ & $\square$ & $\square$ & Training \\
\hline Environmental total quality management & $\square$ & $\square$ & $\square$ & $\square$ & $\square$ & $\square$ & $\square$ & $\square$ & $\square$ & New technologies \\
\hline Environmental total quality management & $\square$ & $\square$ & $\square$ & $\square$ & $\square$ & $\square$ & $\square$ & $\square$ & $\square$ & Promoting green culture \\
\hline Environmental total quality management & $\square$ & $\square$ & $\square$ & $\square$ & $\square$ & $\square$ & $\square$ & $\square$ & $\square$ & Training \\
\hline New technologies & $\square$ & $\square$ & $\square$ & $\square$ & $\square$ & $\square$ & $\square$ & $\square$ & $\square$ & Promoting green culture \\
\hline New technologies & $\square$ & $\square$ & $\square$ & $\square$ & $\square$ & $\square$ & $\square$ & $\square$ & $\square$ & Training \\
\hline New technologies & $\bar{\square}$ & & $\square$ & & $\bar{\square}$ & $\bar{\square}$ & $\bar{\square}$ & $\bar{\square}$ & $\overline{\mathrm{D}}$ & Training \\
\hline
\end{tabular}

\subsection{Examining the relationships using fuzzy ANP}

In this stage, based on pairwise comparison and according to Formula 1 and based on the triangular fuzzy range, we obtain eigenvector

Formula (1)

$$
\begin{gathered}
w_{k}^{s}=\frac{\left(\Pi_{j=1}^{n} a_{k j}^{s}\right)^{\frac{1}{n}}}{\sum_{i=1}^{n}\left(\Pi_{j=1}^{n} a_{i j}^{m}\right)^{\frac{1}{n}}} \quad ; \quad s \in\{l, m, u\} \\
\widetilde{w}_{k}=\left(w_{k}^{l}, w_{k}^{m}, w_{k}^{u}\right) \quad k=1,2,3, \ldots, n
\end{gathered}
$$

Formula 2.

After obtaining specific values, these values are normalized in order to put them in a super matrix according to

Formula (2) 


$$
\mathrm{B}=\frac{\left(\mathrm{a}_{1}+\mathrm{a}_{3}+2 \times \mathrm{a}_{2}\right)}{4}
$$

$B$ is defuzzed form of $\widetilde{A}=\left(a_{1}, a_{2}, a_{3}\right)$

Tables 2 to 7 show the comparison of pairwise comparison their mean calculated (by 8 experts), eigenvectors and fuzzy values of it based on target, measure $A$, measure $B$, measure $C$ and measure $D$ (Azar, 2006)

Table 9: Fuzzy weight steps without considering dependency among steps

\begin{tabular}{|l|c|}
\hline Steps & Fuzzy weights \\
\hline product recycling at the end of its useful life & $0.121 ، 0.138 ، 0.214$ \\
\hline Supporting of the green supply chain by senior managers and middle & $0.273 ، 0.413 ، 0.565$ \\
\hline $\begin{array}{l}\text { Observing the standards required in the purchase of machinery and equipment from technical and } \\
\text { environmental point of view }\end{array}$ & $0.512 ، 0.634 ، 0.017$ \\
\hline Environmental total quality management & $0.088 ، 0.252 ، 0.385$ \\
\hline The use of new technologies for the efficient use of energy & $0.116 ، 0.161 ، 0.314$ \\
\hline Promoting green culture in the workspace & $0.242 ، 0.376 ، 0.554$ \\
\hline Training and providing proper energy consumption patterns & $0.263 ، 0.213 ، 0.065$ \\
\hline
\end{tabular}

In each stage in each section, one of steps was considered as constant step above the matrix and other steps are compared based on it, and thereby their weights are calculated. In fact, there are seven steps here that pairwise comparison matrix should be formed. To determine the final weight, output of main criteria comparison is provided in a super matrix based on targets and interrelations among criteria. This super matrix is known as primary or uneven matrix. (Mansouri, 2007).

Table 10: Super matrix

\begin{tabular}{|c|c|c|c|c|c|c|c|}
\hline & $\begin{array}{l}\text { Product } \\
\text { recycling }\end{array}$ & $\begin{array}{c}\text { senior management } \\
\text { support }\end{array}$ & \begin{tabular}{|c|} 
Observing \\
required standards
\end{tabular} & $\begin{array}{l}\text { Total quality } \\
\text { management }\end{array}$ & $\begin{array}{c}\text { New } \\
\text { technologies }\end{array}$ & $\begin{array}{l}\text { Promoting the } \\
\text { green culture }\end{array}$ & Training \\
\hline Product recycling & (1.1.1) & 0.047 0.065، 0.089 & \begin{tabular}{|c|}
$0.065 ، 0.169$ \\
0.047
\end{tabular} & $\begin{array}{c}0.057 \text { ، } 0.087 \\
0.037\end{array}$ & $\begin{array}{c}0.068 ، 0.093 \\
0.045\end{array}$ & $\begin{array}{c}0.071 ، 0.090 \\
0.055\end{array}$ & $\begin{array}{c}0.214 \\
0.1450 .0191\end{array}$ \\
\hline $\begin{array}{l}\text { senior management } \\
\text { support }\end{array}$ & \begin{tabular}{|c|}
$0.085 ، 0.112$ \\
0.081
\end{tabular} & $(1.1 .1)$ & $\begin{array}{c}0.105 ، 0.231 \\
0.254\end{array}$ & $\begin{array}{c}\cdot 0.123 ، 0.036 \\
0.119\end{array}$ & $\begin{array}{c}0.169 ، 0.171 \\
0.120\end{array}$ & $\begin{array}{c}r 0.252 ، 0.231 \\
0.207\end{array}$ & $\begin{array}{c}0.312 ، 0.235 \\
0.381\end{array}$ \\
\hline $\begin{array}{l}\text { Observing required } \\
\text { standards }\end{array}$ & \begin{tabular}{|c|}
$0.433 ، 0.610$ \\
0.404
\end{tabular} & $\begin{array}{c}0.085 ، 0.112 \\
0.081\end{array}$ & $(1.1 .1)$ & $\begin{array}{c}\cdot 0.061 ، 0.080 \\
0.027\end{array}$ & $\begin{array}{c}0.035 ، 0.165 \\
0.041\end{array}$ & $\begin{array}{c}\cdot 0.047 \text { r } 0.083 \\
0.017\end{array}$ & $\begin{array}{c}\cdot 0.038 ، 0.023 \\
0.041\end{array}$ \\
\hline $\begin{array}{l}\text { Total quality } \\
\text { management }\end{array}$ & $\begin{array}{c}0.252 ، 0.231 \\
0.207\end{array}$ & $0.331 ، 0.412 ، 0.505$ & $\begin{array}{c}0.433 ، 0.610 \\
0.404\end{array}$ & (1.1.1) & $\begin{array}{c}0.433 ، 0.610 \\
0.404\end{array}$ & $\begin{array}{c}0.106 ، 0.123 \\
0.093\end{array}$ & $\begin{array}{c}0.281 ، 0.429 \\
0.177\end{array}$ \\
\hline New technologies & $\begin{array}{c}0.252 ، 0.231 \\
0.207\end{array}$ & $0.331 ، 0.412 ، 0.505$ & $\begin{array}{c}0.433 ، 0.610 \\
0.404\end{array}$ & $\begin{array}{c}0.252 ، 0.231 \\
0.207\end{array}$ & (1.1.1) & $\begin{array}{c}\cdot 0.433 ، 0.610 \\
0.404\end{array}$ & $\begin{array}{c}0.065 ، 0.169 \\
0.047\end{array}$ \\
\hline $\begin{array}{l}\text { Promoting the green } \\
\text { culture }\end{array}$ & $\begin{array}{c}0.169 ، 0.171 \\
0.120\end{array}$ & 0.207 0.252، 0.231 & $\begin{array}{c}0.412 ، 0.505 \\
0.331\end{array}$ & $\begin{array}{c}r 0.433 ، 0.610 \\
0.404\end{array}$ & $\begin{array}{c}\cdot 0.085 ، 0.112 \\
0.081\end{array}$ & (1.1.1) & $\begin{array}{c}\cdot 0.065 \cdot 0.089 \\
0.047\end{array}$ \\
\hline Training & $\begin{array}{c}0.183 \cdot 0.236 \\
0.114\end{array}$ & $0.120 ، 0.169 ، 0.171$ & $\begin{array}{c}0.252 ، 0.231 \\
0.207\end{array}$ & $\begin{array}{c}0.412 ، 0.505 \\
0.331\end{array}$ & $\begin{array}{c}\cdot 0.433 ، 0.610 \\
0.404\end{array}$ & $\begin{array}{c}\cdot 0.412 ، 0.505 \\
0.331\end{array}$ & (1.1.1) \\
\hline
\end{tabular}

In the final stage, my multiplying the considered super matrix (composed of weights of second stage criteria) in the matrix of the criteria weights in the first phase, the final weight is obtained. Then, these fuzzy weights are converted to final weights using area center method. After normalizing the priority of steps, Table 11 was obtained:

Table 11: Final weight and prioritizing the steps and rank of key steps

\begin{tabular}{|l|c|c|c|}
\hline Step & Final weights & Normalized weights & Priority \\
\hline Product recycling & 0.549 & 0.321 & 4 \\
\hline senior management support & 0.468 & 0.256 & 7 \\
\hline Observing required standards & 0.571 & 0.375 & 3 \\
\hline Total quality management & 0.584 & 0.396 & 2 \\
\hline New technologies & 0.682 & 0.413 & 1 \\
\hline Promoting the green culture & 0.491 & 0.274 & 6 \\
\hline Training & 0.524 & 0.309 & 5 \\
\hline
\end{tabular}




\section{Findings of Study}

\subsection{Answer for questions}

1. What is the key steps for successfully implementation of green supply chain in Iran?

The most important identified key steps are as follows, respectively:

- Environmental Total Quality Management

- Training and providing accurate energy consumption patterns

- Supporting green supply chain by senior and middle managers

- Observing required standards in the purchase of machinery and equipment from technical and environmental point of view

- Using new technologies for the efficient use of energy

- Promoting green culture in the workspace of company

- product recycling at the end of its useful life

- What is priority of key steps for successfully implementation of green supply chain in Iran?

- The most important key steps are as follows, respectively:

- Using new technologies for the efficient use of energy

- Environmental Total Quality Management

- Observing required standards in the purchase of machinery and equipment from technical and environmental point of view

- product recycling at the end of its useful life

- Training and providing accurate energy consumption patterns

- Promoting green culture in the workspace of company

- Supporting green supply chain by senior and middle managers

\subsection{Final form of implementing green supply chain in Iran}

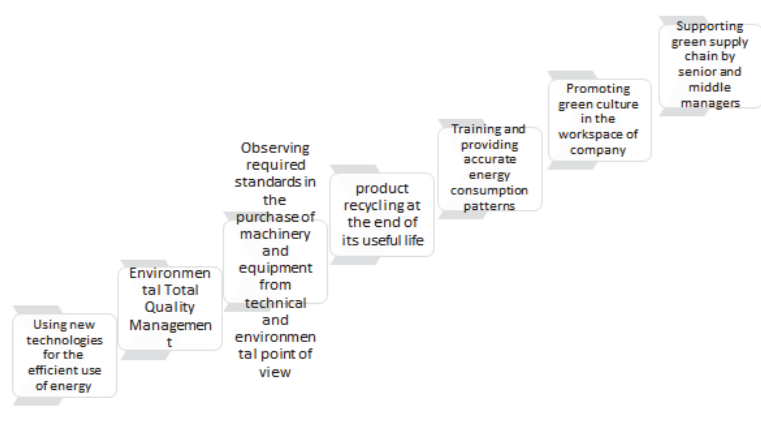

\section{Conclusion}

Studies suggest that, nowadays, environmental management with an emphasis on protection of the environment is one of the most important issues of customers, shareholders, governments, employees and competitors and global pressures have made organizations to produce eco-friendly products and services. Often, it is thought that green supply chain in the sense of reducing or do not using chemical harmful substances, which have been quite wrong impression because chain goes beyond this stage and considers all parts of an organization. In fact, green supply chain is result of link between economic goals and environmental goals of organization.

\section{References}

Kalantari, KH, processing and analyzing data in the Economic and Social Research, Tehran, Sharif Publishing, 2003

Mansouri, M, statistical data analysis using SPSS, Tehran, New Book Publishing, 2007

Azar, A, Statistics and Its Application in Management (statistical analysis), the second edition, Fall 2006 
Ghazanfari, M, Riazee, A, Kazemi, M, supply chain management ; Tadbir Journal No. 117, May 2001, pp 20 to 27.

Saeedi Kia, AA, Motahari Fard, J, Riazee, MT; supply chain management; Method Journal, Tenth Year I, Number 61

Charmchy, HR, the concept of supply chain in the industry and its benefits, Industry Quarterly, Issue 23, Summer 79; $p 6$ to 9 .

Maurice, $\mathrm{C}$ et al, innovation in the supply chain, superior value in after-sales service; Translated by doctor Abdul Reza Rezaei-Nejad, Selected management magazine, Issue 4, February 2000, pp 75 to 82

George P. Martin, E, translated by Norouzzadeh; transforming the supply chain to income chain; new ideas, selected management monthly, No. 8, July 2001, p 5 to 7.

Teimori, providing models for supply chain management system, $\mathrm{PhD}$ dissertation in Industry Engineering- University of Science and Technology, October 1999.

Beard, Colin and Rees, Stephen (2015); Green Teams and the Management of Environmental Change in a UK County Council, Environmental Management and Health, Vol. 11, No. 1, pp. 27-38.

Rao, Purba and Holt, Diane (2010); Do Green Supply Chains Lead to Competitiveness and Economic Performance?, International Journal of Operations \& Production Management, Vol. 25, No. 9, pp. 898-916.

Harris, Lloyd C. and Crane, Andrew (2005); The Greening of Organizational Culture, Journal of Organizational Change Management, Vol. 15, No. 3, pp. 214-234.

Hsu, C. W. and Hu A. H. (2013); Green Supply Chain Management in the Electronic Industry, International Journal of Environ. Sci. Tech. 5 (2), pp. 205-216.

Hsu, Chia-Wei, Kuob, Tsai-Chi, Chenc, Sheng-Hung and Hud, Allen H. (2014); "Using DEMATEL to Develop a Carbon Management Model of Supplier Selection in Green Supply Chain Management", Journal of Cleaner Production Xxx, pp. 1-9. doi:10.1016/j.jclepro.2011.09.012.

Huang, S.J., Chiu, N.H., Chen, L.W., (2013); Integration of the Grey Relational Analysis with Genetic Algorithm for Software Effort Estimation. European Journal of Operational Research 188, 898-909.

Huang, Niven (2006); Eco-Efficiency and an Overview of Green Productivity, Conference on Enhancing Competitiveness Through Green Productivity, China, 25-27 May.

Hwa, Tay Joo (2006); Green Productivity \& Supply Chain Management, Conference on Enhancing Competitiveness Through Green Productivity, China, 25-27 May.

Ip, W.H., Chan, S.L. and Lam, C.Y. (2014); Modeling supply chain performance and stability. Industrial Management \& Data Systems, Vol.111, No. 8, pp. 1332-1354. DOI 10.1108/02635571111171649.

Koshibu, Hiroaki (2006); Greening the Market: The Effort by Fuji Xerox \& The Green Purchasing Network, Japan, Conference on Enhancing Competitiveness Through Green Productivity, China, 25-27 May.

Kotzab, Herbert, Munch, Hilde M., Faultrier, Brigitte de and Teller Christoph (2014); Environmental Retail Supply Chains: When Global Goliaths Become Environmental Davids, International Journal of Retail \& Distribution Management, Vol. 39, No. 9, pp. 658-681. DOI 10.1108/09590551111159332.

Large, Rudolf O. and Thomsen, Cristina Gimenez (2014); Drivers of Green Supply Management Performance: Evidence from Germany, Journal of Purchasing \& Supply Management 17. pp: 176-184. doi: 10. 1016/j.pursup. 2011.04.006.

Hwa, Tay Joo (2006); Green Productivity \& Supply Chain Management, Conference on Enhancing Competitiveness Through Green Productivity, China, 25-27

Sheu, Jiuh-Biing (2013); Green Supply Chain Management, Reverse Logistics and Nuclear Power Generation, Transportation Research Part E44, pp. 19-46.

Yu, Ning (2006); The Creen Consumption Movement: The Roles of Government, Business, Academia, NGOs and Consumers, Conference on Enhancing Competitiveness Through Green Productivity, China, 25-27 May.

Ninlawan, C., Seksan, P., Tossapol K. and Pilada, W. (2010); The Implementation of Green Supply Chain Management Practices in Electronics Industry, Proceedings of the International Multiconference of Engineers and Computer Scientists, Hong Kong, March $17-19$. 